\title{
"Not Like a Big Gap, Something We Could Handle": Facilitating Shifts in Paradigm in the Supervision of Mathematics Graduates upon Entry into Mathematics Education
}

\author{
Elena Nardi
}

Published online: 23 April 2015

(C) Springer International Publishing Switzerland 2015

\begin{abstract}
Mathematics is the discipline that a significant majority of most incoming researchers in mathematics education have prior qualifications and experience in. Upon entry into the field of mathematics education research, these newcomers-often students on a postgraduate programme in mathematics education-need a broadened understanding on how to read, converse, write and conduct research in the largely unfamiliar territory of mathematics education. The intervention into the practices of post-graduate teaching and supervision in the field of mathematics education that I describe here aims at fostering this broadened understanding and thus facilitating newcomers' participation in the practices of the mathematics education research community. Here I outline the theoretical underpinnings of the intervention and exemplify one of its parts (an Activity Set designed to facilitate incoming students' engagement with the mathematics education research literature). I supplement the discussion of the intervention with comments sampled from student interview and student written evaluation data as well as observations of the activities' implementation. The main themes touched upon include: learning how to identify appropriate mathematics education literature; reading increasingly more complex writings in mathematics education; coping with the complexity of literate mathematics education discourse; working towards a contextualised understanding of literate mathematics education discourse. I conclude with indicating the directions that the intervention, and its evaluation, is currently taking and a brief discussion of broader implications, theoretical as well as concerning the supervision and teaching of post-graduate students in mathematics education.
\end{abstract}

Keywords Post-graduate studies in mathematics education - supervisory practices · epistemological shifts $\cdot$ transition

E. Nardi $(\bowtie)$

University of East Anglia, Norwich NR4 7TJ, UK

e-mail: E.Nardi@uea.ac.uk 


\section{Introduction}

Within mathematics education, working towards membership of the scholarly community often implies a rethinking of epistemological beliefs - as evident in the experiences of mathematics educators and university mathematicians engaging with collaborative research (see, for example, (Nardi 2008, p. 257-292), including a review of literature on this matter). This is even more acutely true for those who arrive in mathematics education postgraduate study from a purely mathematical background. In a nutshell, the area where a shift of epistemological beliefs often emerges as necessary is towards what has been called in the literature (e.g., Boaler et al., ibid., particularly pp. 497-516) a less absolutist, more contextually bound, more relativist and multiplist perspective on what constitutes knowledge (in mathematics education) and how it is constructed and shared.

Boaler et al. (ibid.) set out their exploration of what the training of new researchers in mathematics education needs to attend to from two issues that their experience has highlighted as seminal. First, they note, educational practitioners who embark on research often start off with a view of systematic enquiry as a way to 'show, prove, convince' of 'what works' (p. 492). A further issue, they add, emerges when 'new researchers who know they need to become familiar with relevant studies in their field but conceive of this task as a goal in its own sake, or even as a ritual, signalling to other members of the community that they are well read' (p. 492). Both these issues are quintessential and Boaler et al. have a formidable stab at them in their chapter. Their treatment of these issues - 'considering research from the perspective of its practices' (p. 493) - begins to highlight the necessary epistemological shifts that engagement with mathematics education research entails, whether the new researcher sets out from an educational practitioner background or - as is the focus of this paper - from a mathematician / mathematics graduate background. In this paper, I focus on a variation on the theme of epistemological shifts raised by Boaler et al., namely those that are germane to a transition from systematic enquiry in mathematics to systematic enquiry in mathematics education.

As Boaler et al. noted in 2003 - and is still the case - the body of work on the preparation of new mathematics education researchers is 'small but expanding' ( $\mathrm{p}$. 494). This body of work engages with the many and varied faces of what awaits incoming mathematics education researchers. Upon entry in the field, newcomers 'need at minimum to understand and respect the nature of different research traditions and paradigms' and be 'sufficiently open to appreciate the value of different perspectives and frameworks' (p. 496). Their 'ability to do so will depend, in part, upon being knowledgeable about the philosophical and epistemological foundations of different paradigms and the nature of evidence they provide." (pp. 496-7). Learning how to exercise 'both imagination and discipline' (p. 497) is at the heart of the skills that newcomers to the field need to develop - and the fostering of these skills is at the heart of what their supervision and teaching needs to focus on.

Of particular resonance with the work I present in this paper is Boaler et al.'s observation that "the preparation of new mathematics education researchers may be better informed if more explicit attention is given to the work in which they will engage" (p. 497, my emphasis) - with 'work' here alluding to the 'active process of investigation' (p. 497), rather than to static, product-oriented notions of knowledge these researchers need to acquire. Boaler et al.'s 'explicit and purposeful focus on 
research practices' (p. 517) such as 'reading, formulating a research question, using data carefully to make and ground claims, moving from the particular to the general, considering mathematics, and communicating research findings' (p. 497) aligns well with the design of the part of the intervention that I focus on in this paper: activities that relate to engaging newcomers with the mathematics education research literature (touched upon by Boaler et al. in their section on 'Reading', p. 497-9). I elaborate the activities and their rationale in the sections that follow but, in a nutshell, their aim is to facilitate the newcomers' entry into a world of vast, very diverse, multi-modal readings; to foster in them the capacity to cope with the complexity of engaging with the arguments and findings of others; and, to do so while locating their own research, and prior learning and teaching experiences in mathematics, in the realm of these arguments and findings.

The set of activities that I present here also responds to what Batanero et al. (1994) noted as the predominance in the provision to post-graduate students of knowledge, rather than activity based programmes in mathematics education research - namely programmes designed around a curriculum of knowledge acquisition, with knowledge to be applied later by the students, in subsequent phases of their study, in their dissertation research. Recent digests of developments in this area (e.g., Liljedahl et al. 2013; Reys and Kilpatrick 2001) have been mapping, and acknowledging the substantial value of, a mentorship / participation / activity oriented approach to the preparation of new mathematics education researchers. The work presented in this paper is aligned with, and aims to further, the works that adopt this approach.

Mathematics education, the discipline of my immediate expertise and the discipline within which the activity sets of the trial is being carried out, is a suitable Example Case discipline: mathematics education postgraduate students, especially those engaged in university-level mathematics education research, are likely to come from a background in mathematics. The shift from a Science to a Social Sciences paradigm for these students is typically a very pronounced part of their transitional experience.

In what follows I present the rationale and contents of the intervention. First however I outline briefly how the intervention is embedded into a larger set of considerations and principles that underwrite the design of the postgraduate Mathematics Education programme that this intervention belongs to.

\section{Facing the Multi-Layered Unfamiliarity in the Transition to Post-Graduate Study: Considerations and Principles}

In today's global and highly mobile educational community students arrive at their graduate studies often from different linguistic, cultural, pedagogical and scientific backgrounds. The case of an international student who embarks on study for a Masters or a doctorate in a language other than their first, from a non-Western background and in a discipline other than that of their undergraduate studies is quite common (Su 2012). This student needs a broadened understanding on how to read, converse, write and conduct research in academic environments that are unfamiliar in many ways (Magyar and Robinson-Pant 2011).

The educational research literature (e.g., Adamson et al. 2012, p. 12-35) has described this unfamiliarity as a key aspect of the post-graduate student learning 
experience; and the overcoming of this unfamiliarity as a key issue that the teaching and supervision of post-graduate students needs to address (Varghese 2012). The intervention into the teaching and learning practices of post-graduate teaching and supervision that I describe in this paper aims exactly at that: to facilitate students' gaining of aforementioned broadened understanding and thus facilitate their transition to post-graduate studies. In doing so I take cue from research in this area that calls for a reconceptualization of the Higher Education curriculum, pedagogy and assessment on this matter, and focus this small-scale trial, itself part of a plan for a larger study, on aspects of pedagogy.

Research into the challenges of the transition from undergraduate to postgraduate studies has been growing rapidly in recent years, often in connection with the move 'from elite to mass higher education' (Sharpham 1993) or the 'widening participation' agenda that has been driving developments within Higher Education (HE) in several countries (e.g., in the UK, as evidenced in the reports by HEFCE, the Higher Education Funding Council of England). A particular dimension of said widening participation is connected, certainly in the UK, with the increasing influx of international students and the urgency of addressing their needs, often starting from a questioning of longstanding, dominant discourses (e.g., Su 2011; Adamson et al. 2012; Magyar and Robinson-Pant 2011).

Often this research includes direct, self-reporting studies of students' perceived needs and perceptions of effective supervisory practices (e.g., Egan et al. 2009; Pyhalto et al. 2009). Alongside a plethora of supervisory practice guides (e.g., Chiappetta-Swanson, and Watt 2011), much of this research tends to focus on generic issues. As evidenced in the bulk of the articles published in the International Journal of Doctoral Studies, (http://www.informingscience.us/icarus/journals/ijds/), established in 2006, these include: interpersonal aspects of the relationship between supervisor and supervisee; accessibility and availability of the supervisor; academic compatibility; and, time management and expectations. Several models of supervisory practice - such as Sonneveld's model (Oost and Sonneveld 2007), which focusses on subject knowledge, research expertise, interpersonal relationship, management of doctoral process, coaching / teaching and socialisation and integration in a research community, or the Lovitts \& Lee model (Lovitts 2007) which highlights themes such as longevity of supervisor-supervisee relationships, enthusiasm, sensitivity, appreciation of individual difference, respect, unselfishness, support outside sphere and teaching /communication skills - have also emerged as both research and practice tools in recent years.

Findings concerning generic issues such as that 'especially international students and those in soft ${ }^{1}$ disciplines, require a personal and holistic style of supervision' (Egan et al 2009, p. 337) are of utmost significance. However of at least equal gravity is the focus on practices that aim to foster skills and attitudes in postgraduate students which are epistemologically specific, namely specific to the discipline - in our case: mathematics education - they are coming into. Attention on these is also part of a longer-term perspective on post-graduate studies as a stepping stone to a career in research (e.g., Shacham and Od-Cohen 2009).

\footnotetext{
${ }^{1}$ This term typically refers to the social sciences, of which mathematics education is widely perceived to be one. See extended comment on this in the next section.
} 
The project I describe in this paper aims to make a contribution in these respects (epistemologically specific, long-term) and builds on a relatively small body of work in this area - aptly summarised in (Boaler et al. 2003) and evident in several chapters in (Sierpinska and Kilpatrick 1998; most explicitly in the chapter by Gione, p. 117-127). In what follows I outline the theoretical foundations on which the project is built.

At this juncture I need to note that one underlying assumption of the work presented here is of mathematics education as an area of educational research, and therefore a part of the social sciences. This is a widely but not universally accepted assumption; in fact, it is a culturally dependent assumption. For example, in continental Europe, chairs in didactics of mathematics are usually located in science faculties, often alongside those in applied or pure mathematics. However, regardless of whether mathematics education research is carried out by researchers whose affiliation is in a mathematics, education or another department, the epistemological differences between the two fields are profound and extensively documented (e.g.,: Sierpinska and Kilpatrick 1998, pp. 445-548; Nardi 2008, pp. 257-292).

Engaged Pedagogy As Pyhalto et al. (2009) identified there is 'an urgent need for more effective means of fostering $\mathrm{PhD}$ students' experience of active agency within scholarly communities' (p. 221). Much in the spirit of Gunzenhauser and Gerstl-Pepin (2006), the teaching and supervision practices trialled in this project reflect the prioritising of 'an engaged pedagogy, which represents a shift in emphasis from instrumental training in research methods to an approach in which students develop appreciation for complex possibilities' (p. 319). In the activities described in what follows these 'complex possibilities' include engagement with a step-by-step growing multiplicity of resources, as for example, evident in Activities 1 and 3.

Cultural Sensitivity Particularly for those whose background was shaped away from where much of the educational research dominating the publication venues was conducted in (e.g., graduate students of non-Western backgrounds), they, 'valued as knowing subjects, may enrich their investigations of educational problems and questions with epistemologies and theoretical perspectives that value their individual identities' (p.319) and inform their emergent research plans. Away from a 'dominant discourse' that 'appears to centre on what universities do to fit international students into their existing cultures' (Turner and Robson 2008, p. 70), the project I describe in this paper aims to contribute to what the 2007 UK Higher Education Academy Report (Caruana and Spurling 2007, p. 64) outlines as a much needed shift from merely 'awareness of difference' to 'valuing difference' and integrating this valuing into pedagogical practice in substantive ways - in other words the shift from 'symbolic' to 'transformative' internationalization (ibid. p. 126). The activities described in what follows meet this 'transformative' proviso in the dialectical ways in which they invite students to engage with the mathematics education literature: e.g., in Activity 2b, students are invited to complement pre-set readings with relevant readings from their own cultural and educational background, or with accounts of their own learning and teaching experiences.

Independence, Creativity and Critical Thinking These are often described (e.g., Adler and Adler 2005) as marks of the emerging membership to the scholarly community: 
decisions on what to focus on, the move from appropriating to creating knowledge, the growth of an epistemological perspective (for Adler and Adler's sociology students the 'sociological eye', p. 11); the flexibility of moving between immersion into the specificity of one's own research and contributing to abstract theory; and so many other features of what Baker and Pifer (2011) call 'transition to independence' (p. 5). Each one of the activities described in what follows meets this 'independence' proviso in the ways in which the activities invite students to transcend the execution of pre-set tasks (such as engage with pre-set readings) and do all of the following: search for additional resources; select ones that are closely related to the themes of each session; prepare, and conduct, presentations; and, respond and discuss their presentations as well as those of others.

So far I have set out the foundations of the project as being built around the principles of: engaged pedagogy and participation; cultural sensitivity; and, independence, creativity and critical thinking. The spirit of the intervention is captured well by De Vita and Case (2003) who outline the role of the tertiary level teacher as 'helping students construct understandings that are progressively more mature and critical' ( $p$. 393). They thus propose 'the pursuit of didactic strategies aimed at facilitating processes of self-enquiry, critical reflection, mutual dialogue and questioning' that lead 'to a more participative and student-centred approach' in which students interact 'with the content and with each other' and are thus 'exposed to multiple perspectives and foster cultural understanding' (ibid.). I note that in the context of the intervention presented and discussed here 'multiple perspectives' is taken as meaning both the varied views that students may bring from their diverse cultural, educational, disciplinary etc. backgrounds as well as the multiplicity of theoretical perspectives that is such a defining characteristic of mathematics education research.

I now present the rationale and contents of the intervention.

\section{Welcoming Newcomers to Mathematics Education Research: Aims and Methods of the Intervention}

The intervention in the teaching and supervisory practices I describe in this paper is designed, implemented and evaluated in collaboration with post-graduate students in my institution. I do so in consultation with the relevant literature and through drawing on personal and professional experience that I have accumulated over 20 years of my own post-graduate studies and post-graduate supervision and teaching.

Key to this intervention is also my on-going work with colleagues from my institution, whose own background is a valuable resource to this initiative. Involving colleagues is crucial also in that the ways in which supervisors work with students is naturally filtered through their own interpretations of these activities - and, of how these activities can be tailored to address their students' specific needs.

Furthermore, since the inception of the Research in Mathematics Education Group at my institution in 2003, the post-graduate student cohorts (on the Masters and doctoral programmes) have been steadily informing the formation of the trialled practices and activities that I exemplify from in this paper. For example, of the 17 completed/current doctoral students of the Group (at the time of writing), all come from a mathematics or 
science background and 13 are non-UK students (EU: 3; non-EU: 10). The Group has at least one visiting doctoral student per year and the intervention described here involved these students too. The intervention has also involved 20 Masters students, even though the data discussed in this paper originate in the experiences (evaluations and interviews) of a subset of 6 of these students, from one academic year's cohort.

The intervention has been designed in the spirit of developmental research (e.g., Sierpinska and Kilpatrick, ibid., chapter by Gravemeijer: pp. 277-295). Sets of activities are trialled in the course of the academic year's post-graduate teaching and supervision. These aim to address key issues of the transition to post-graduate studies that I have observed as seminal over several years of experience and are highlighted as such also in the relevant literature. Realistically, this small-scale, single institution intervention can only address some of these key issues. In subsequent phases of the project the Group aims to engage colleagues and programmes in other institutions, particularly through its research partnerships and steady stream of academic visits.

At the heart of the activity sets that I exemplify from is to offer a challenging, yet smooth, transition to mathematics education research. The issue of smoothness is particularly poignant in this transition. As several of the authors I quote in the previous section note (particularly Boaler et al.) post-graduate programmes in mathematics education tend to contain sizeable leaps from the often closed, well-defined tasks that students are expected to engage with in day-to-day sessions to the formidable demands of, say, a substantial literature review in a topic of their choice as they prepare for their dissertation research. This is even more poignant for mathematics graduates arriving at a postgraduate programme in mathematics education with often only distant memories, say from essay writing in school, of what reading and writing for academic purposes entails.

The activity sets that are designed to address some of the challenges of said transition concern the following three areas: Engaging with Mathematics Education Research Literature; Forming the Conceptual/Theoretical Framework of a Mathematics Education Research Project; Choosing and Applying Data Analysis Methods in Mathematics Education Research. In this paper I focus on the first set. To this aim I draw on data collected during the implementation and evaluation of the activities in order to describe and analyse the students' participation in the activities; and, explore how subsequent versions of the activities can be amended to address students' needs more precisely and effectively.

As outlined earlier, the activity sets are trialled and evaluated with new cohorts of Masters and doctoral level students. One such set, the focus of this paper, concerning the theme Engaging with Mathematics Education Research Literature is presented in Fig. 1. In this paper I deploy the experience of implementing and evaluating this set of activities in order to discuss the issue of paradigm shifts that a transition to mathematics education research entails, particularly for those students who arrive at postgraduate studies with a primarily mathematical background. I note that the needs of the student cohorts who participate in the activities (Masters and doctoral; UK and non-UK; mathematics and other backgrounds; with varying teaching or other professional experience) are distinct and a discussion of these needs should not be conflated into one single investigation. However, the profile of most participating students is such that a concurrent consideration of issues is often necessary, even potent. My consideration of student data is alert to this variation of student profile and this variation of issues. 


\section{Engaging with Mathematics Education Research Literature}

These activities aim to facilitate incoming post-graduate mathematics education students' Engaging with Mathematics Education Research Literature particularly in relation to:

- Searching: identifying relevant mathematics education research literature

- Reading: critical reading of mathematics education research literature

- Writing: reviewing mathematics education research literature

- Conversing: presenting and discussing mathematics education research literature.

Activity 1: In an early session, students engage in a discussion of various types of publications (such as books, journal papers, reports, policy documents) and of their status in research writing.

Activity 2: In the sessions that follow, the students are asked to prepare as follows:

a) Read pre-specified texts, typically book chapters or journal papers.

b) Produce/identify a piece of writing (Data Sample) that illustrates how they relate their reading for the session with what they have read or experienced before. This can be a publication from their own cultural and educational context, or a short account of a mathematics teaching or learning experience that relates to the theme of the session.

This is their Short Contribution I.

c) Identify a journal paper that matches the theme of the session from a particular journal, typically a leading journal in the field.

d) Write a short account of their chosen paper that provides

- a summary of the paper,

- their views on the paper, and,

- how (if at all) the paper relates to their own research interests and plans.

This is their Short Contribution II.

Activity 3: In ensuing weeks the range of sources that the students are asked to draw on broadens (from one to several pre-specified journals, then non-pre-specified)

Activity 4: Brief presentations of Short Contributions $I$ and II occur during the session.

Activity 5: Brief presentations are accompanied by discussion with the group.

A key characteristic of Activities 1-5: students are encouraged and expected to draw upon the knowledge and experience they acquired in their own educational and cultural background (own experiences as well as such as works published, e.g., in their native language).

Fig. 1 Activity set on engaging with mathematics education research literature

I trial these sets of activities during sessions of group and individual tutorials. I report the execution of the activities in field-notes produced by myself and the students, typically in email exchanges that follow the sessions. I often draft these during the session and finalise, through exchanges with the students, immediately after.

Evaluation of the trialled activities takes place through an evaluative questionnaire and a group interview. The data quoted in this paper originate from five students in the 
cohort of one academic year. Participation in the activities is subsumed in the normal provision to the students. However, their written consent was obtained for using observations from the sessions, responses to the evaluative questionnaires and the audio-recorded group discussions of their experiences of the intervention. Their participation in the evaluation phase was on a volunteering basis. Anonymity has been kept throughout, e.g., through the option to submit anonymised questionnaire responses. Confidentiality has been secured through using pseudonyms in any quotations from the data.

\section{Sample Activity set: Engaging with Mathematics Education Research Literature}

\section{Context, Content and Aims}

A post-graduate international student in mathematics education - or a student with a background in the sciences who arrives in the UK in order to complete post-graduate studies in the social sciences - is tasked with formidable challenges. Apart from carrying out their studies in a language that is often other than their native language - as well as learning the language of the field they are entering - this student faces novelty on several grounds. They would be required, for instance, to read the social sciences research literature that: is often lengthier than the research literature in the sciences; often uses a breadth of related, subtly different but not equivalent terms to describe similar phenomena; can be perceived as re-formulating the obvious or experientially true in complex terminology, while in fact it purports to establish a theoretically sound discourse for the discipline; and, is typically rather more open to multiple interpretations than the bulk of scientific texts they are accustomed to.

This student is expected to identify, read, reflect upon, converse and write about this literature, often in a matter of months. In Fig. 1 I sample some activities that I currently invite my Masters and doctoral students to participate in during the early months of their arrival. I then outline the empirical origins and rationale for each activity - in resonance with the observations on the type and scope of reading and writing that Boaler et al. (ibid, particularly those on pp. 497-499 and pp. 512-513) highlight as pertinent in the transition to post-graduate studies in mathematics education. My particular focus in this paper is on the paradigmatic shifts that students with a primarily mathematics background experience in the transition to mathematics education research. My account of Activities 1-5 is therefore skewed towards emphasising issues related to these shifts - even though I note that Activities 1-5 were conceived as targeting a multitude of issues, mirroring the multitude of needs of the students in the studied cohorts. I also note that all references to the structure and content of the modules in which the intervention has been implemented are valid for the academic years between 2007-8 and 2013-4.

\section{Empirical Origins and Theoretical Rationales for Activities 1-5}

Activity 1. Discussion of Types of Publications and Their Status in Research Writing The early sessions of the Masters in Mathematics Education are partly dedicated to what we call The world of mathematics education research. In these, types of 
mathematics education publications are discussed in terms of intended readership and distinguished as academic (e.g., a paper in Educational Studies in Mathematics; a peerreviewed, research-based monograph/edited book/book chapter; a $P M E^{2}$ Research Report etc.), professional (e.g., a paper in Mathematics Teaching, the official journal of UK's ATM, Association of Teachers of Mathematics) and policy related (e.g., a government-commissioned report such as the UK's 2004 Smith Report on post-14 mathematics). Students are encouraged to consider this distinction in terms of types of publication they are familiar with. Typically the mathematics graduates on the course appear to be more familiar with undergraduate mathematics textbooks and, to some extent, with publications in mathematics journals. Many overseas students typically put forward influential government reports from their home countries as examples of what they perceive a publication in mathematics education to be. All along, the students are asked to offer counterpart information about analogous or equivalent activity from within their own backgrounds.

The discussion is interspersed with sharing information about key conferences and symposia in mathematics education, national and international, and a brief historical account all the way back to 1908 and the establishment of ICMI. ${ }^{3}$ Through this discussion, the students are invited to perceive the launch of their mathematics education post-graduate studies as inauguration into the scholarly community of mathematics education. I note that these sessions are also attended by incoming doctoral students who are expected to already hold a Masters qualification in (Mathematics) Education. The experience of these students operates as a helpful bridge in these early discussions.

Activity 2. Reading pre-Specified Texts and Identifying two Related Texts (Insider, Outsider) As we launch into the thematic sessions of the Masters programme, preparation for each session tends to be highly regimented (2a) but in tandem with the expectations that:

- The reading is embedded into own prior readings and experiences ( $2 \mathrm{~b}$, 'insider');

- The reading will be enriched with further readings (2c, 'outsider'); and,

- A rationale will be put forward for the choice of this further reading (2d).

(2b) and (2d) require of students to produce a small piece of writing for each session. Intertwined with the students' inauguration into the world of mathematics education research, these exercises aim to foster the perception that writing is paramount; and, acquiring the skill to write with the rigour and sophistication expected at this level is feasible through constant and regular practice. This applies equally to the mathematics graduates on the course (who may not have written in this 'genre' for a long time, if at all) and the non-UK students (who are writing in a language other than their own). In what follows I illustrate how this is operationalised with an example.

Example: Engaging With the Range of Theoretical Perspectives in Mathematics Education Research The module Introduction to Research in Mathematics Education,

\footnotetext{
${ }^{2} \mathrm{PME}$ is an abbreviation of the International Group for Psychology in Mathematics Education established in 1976 (http://www.igpme.org/).

${ }^{3}$ International Commission on Mathematical Instruction (http://www.mathunion.org/icmi/)
} 
attended by Masters in Mathematics Education students as well as Year 1 doctoral students included five sessions on key theoretical constructs used in mathematics education research. Two sessions were on developmental / cognitive approaches; and, three were on sociocultural, discursive and anthropological approaches. In the first of the sessions dedicated to developmental / cognitive approaches in (2a) the students were expected to read two papers that are introduced to them as seminal in the realm of said approaches and therefore quintessential readings for anyone wishing to become familiar with the rise of these approaches in mathematics education research in the 1970s and 1980s: Richard Skemp's 1976 Mathematics Teaching article on Instrumental and Relational Understanding and David Tall and Shlomo Vinner's 1981 ESM paper on Concept image - Concept definition.

To give a flavour of how students respond to the tasks that Activities 1 and 2b-d invites them to engage, here is how one student, a then recent mathematics graduate (international, non-EU) responded. In (2b) she wrote a short account in which she recollected her first encounter with the concept of limit. As part of (2c) she brought along a PME Research Report on a study that used the Concept-image, concept definition construct to explore students' understanding of limits in a university of her country. And, in (2d) she commented on the use of the construct in her paper of choice and related this to her own emerging research plans for her dissertation (which at the time involved students' first encounters with key concepts in Calculus).

As I mentioned earlier, within (2a), and towards the aims of this particular session, the students are asked to read two texts (Skemp's and Tall \& Vinner's) that appeared at a time when mathematics education was at a turning point of its growth into an academic discipline, mathematics education research was largely influenced by educational and cognitive psychology and PME was being founded. ${ }^{4}$ Within (2c) the students are asked to identify research texts, from that era or thereafter, that report research which deploys these theoretical constructs. They are thus encouraged to find out the scope and impact of these works in the field as well as locate their origins in the disciplinary context that allowed these works to emerge. In the sessions that follow the pre-specified readings zoom out of developmental approaches and shift attention to the sociocultural, discursive and anthropological approaches that marked developments in the field, particularly from the 1990s onwards. For instance, one of the activities of the module - and indeed its first formally assessed assignment - asks students to demonstrate their emerging understanding of the multiplicity of theoretical perspectives within mathematics education through identifying, and writing a reflective account on, two publications that report studies in a topic of mathematics education research of the student's choice which have approached the topic from different theoretical perspectives. As an example of the choices that students make at this juncture, the two studies put forward by a student interested in the topic students' learning of the concept of function were (Sajka 2003) and (Moschkovich 2004): the first reports a case study of a student's work on functions approached through the developmental construct of procepts, and the second through the sociocultural construct of appropriation through

\footnotetext{
${ }^{4}$ Inevitably the module and activities described in this paper have themselves been borne out of the enculturation into the field of mathematics education of the researchers (myself and colleagues) who design and deliver these activities. The activities are therefore deeply embedded into the forms that this enculturation (in this case: geared towards the English speaking publication venues and towards the work of organisations such as PME and ICMI) has had over the years.
} 
interaction with a knowledgeable other. I note that elaborating further how this shift takes place falls more within the remit of the other two transition activity sets mentioned in the Aims and Methods section - and therefore is not within the immediate scope of this paper. However it is also pertinent to stress the intertwined nature of the activity sets and that shifting students' attention towards the multiplicity of theoretical perspectives within mathematics education is part and parcel of the enterprise across the three activity sets.

Activity 3. Broadening the Range of Sources As the thematic sessions of the Masters programme continue to unfold, the instructions for preparing for (2b) and (2d) gradually broaden and relax. In order to facilitate, and accelerate, the students' familiarisation with key publication venues in the field, they are asked to prepare for (2d)

- Through searching for journal papers in Educational Studies in Mathematics;

- Then, in a few more journals (Journal for Research in Mathematics Education, Journal of Mathematical Behaviour, For the Learning of Mathematics);

- Then, a list of about ten international, peer-reviewed journals held in my institution's library. By the end of the module the list has opened up to include practically most peer-reviewed published work in mathematics education research.

I return to elaborating the substantial impact that the stepwise character of Activity 3 has through sampling of the evaluative data in the next section.

Activity 4. Brief Presentations of Short Contributions I and II The rationale for the presentations by the students of the short contributions they have prepared is that these presentations are the stepping stone towards engagement with debate, an essential disciplinary characteristic of mathematics education research. I note that the prospect of even informal presentation at this stage of their studies is daunting for most students. It is therefore deemed as perfectly acceptable that students may prefer that, at least to start with, their presentation can consist of reading out to the group their Short Contributions; and, for non-native speakers or those unaccustomed to writing fullyfledged narratives (the latter is a frequent occurrence amongst the recent mathematics graduates on the course) that these Short Contributions are in the form of notes, or bullet lists; and, that they deploy the visual support of slideshows such as Powerpoint.

Activity 5. Brief Presentations are Accompanied by Discussion With the Group As the presentations within Activity 4 are planned as stepping stones towards engagement with collective debate, following these presentations with group discussion is essential. Again, some scaffolding is necessary in the early implementations of Activity 5: students often arrive from educational and cultural backgrounds which have provided minimal opportunity - or appreciation for - debate and critique (particularly of learned colleagues or professors). I have found this applying both to students with cultural origins outside the Western traditions of my institution but - crucially to the purposes of this paper - also to students enrolling on the course straight after undergraduate studies in mathematics. Students have been reluctant to scrutinise each other's selection of readings, and writings (e.g., within Activity 2b, c, d). To encourage engagement with a multiplicity of perspectives and the questioning of authority (mine, as well as those of their peers), Activity 5 has 
included the nomination of reactors (therefore avoiding exclusive reliance on impromptu reactions to the presentations during a session) and the frequent weaving into the sessions of references to the experiences (less or more successful) of previous cohorts on the same tasks. Both of these tactics seem to alleviate some of the pressures that the students experience, particularly in the early parts of the course.

I note that particularly Activities 4 and 5 serve a broader purpose, referenced explicitly in the course specifications of all postgraduate programmes in this institution (and I believe those of many other institutions): to foster an understanding of how paramount these ways of engagement with research are and how regular participation in these practices can facilitate the acquisition of presentation and discussion skills.

To elaborate further some of the issues I touched upon in this section, I now turn to the experiences of one particular cohort of five students. To this aim I draw on their recorded evaluative group interview and questionnaires - and to the fieldnotes from the implementation of Activities 1-5 throughout the first semester of their Masters studies. While the account preserves the diversity of views voiced by all participants, the focus occasionally shifts on a particularly articulate member of the cohort, Sophia, whose profile I outline in the beginning of the section, mostly through her written evaluative data (Part I). Following Sophia's account which serves as an overarching set of comments that covers issues such as the usefulness of the stepwise character of the activities, I then proceed to a narrative account of the evaluative interview with the whole cohort (Part II) that elaborates Sophia's comments. The narrative zooms in the occasions where the group discussed their experiences of Activities 1-5 explicitly: it starts with broad evaluative comments on how the activity set facilitated their multitiered transition into post-graduate studies in mathematics education; it then proceeds with a closer examination of four themes (identifying appropriate literature; increasingly more complex reading; complexity of literate mathematics education discourse; contextualised understanding of literate mathematics education discourse).

\section{Experiencing Activities 1-5, Part I: Sophia}

Sophia obtained her first degree in mathematics only weeks prior to her enrolment on the Masters in Mathematics Education. She was an international student (EU) and a nonnative speaker of English. Throughout her Masters her participation was positive and enthusiastic and this is reflected in her written evaluation of the experience of Activities 1-5. Sophia comments on the gradation of difficulty of the tasks within the Activities and acknowledges some value in this gradation ('the tasks gradually became more difficult, but we also became more familiar with the way of working on them...'). She recognizes that 'the freedom to choose a paper (more practical or looking at different aspects of the focus of the lecture) made the topic more clear [sic]'. Adding to this clarity was the supplementary role of her peers' more substantial teaching experience: '.. we could see the views or the thoughts that the other classmates had regarding the topic and the practice of those theories, as they were more experienced teachers and had different background from me...' Finally she encapsulates how the network of reading, writing, presenting and discussing tasks assisted her gradual adoption of skills and practices that are bound to be crucial in subsequent parts of her studies: 
'...coming from an environment where I didn't have to present anything in oral form, it was difficult for me to present a paper, even to express my thoughts on the readings, but with the way the tasks were designed, starting with reading something we wrote about the paper, and then slowly talking more about it in the group, and finally doing a presentations, made it easier'.

I now turn to the views of the whole cohort (Part II) to elaborate several of the issues that Sophia highlights. These are indicated above in bold. I note that the students were fully aware that they were engaging with Activities 1-5 throughout the semester as their preparation sheets, distributed on a weekly basis, reflected the structure of Activities 1-5 explicitly. In various parts of the recording it is this structure that the students allude to when they talk about 'the way this [module] was taught' etc. The instructor referred to in the narrative is me. It is to the credit of the group that they agreed to share their experiences of - and critical perspectives on - Activities 1-5 directly with me, both through the written and the audio data that form the evidence base of this paper. This discussion took place after I could any longer influence their performance scores but I see it nonetheless as evidence of the maturity, and mutual trust and goodwill, which had been built up on the way. Of the four students, other than Sophia, participating in what follows all but Victoria are international students with varying degrees of involvement either in mathematics teacher education or in mathematics teaching in their home countries.

\section{Experiencing Activities 1-5, Part II: The Group}

The discussion sets out from responses to the request for overall impressions of the experience of Activities 1-5. Maalik starts the responses off by stating that he 'liked it a lot, from the first to the last session'. He alludes to the stepwise format of Activities 15, as the method used 'from session to session, from subject to subject'. Sophia agrees and elaborates further: 'the whole thing made us do different things and acquire different skills [...] through asking us to do certain parts made us more equipped for doing other parts.' She stresses that all three 'transitions' that related to their studies (from undergraduate to graduate studies, from their native languages to English and from mathematics to mathematics education) she 'could see [her]self in those'. 'And the whole thing, how the whole session was scheduled, made the transition more easy [sic] to happen and was very helpful. If you asked us what you asked us in the last session I would say 'I cannot do this!'. The 'flow' of the experience, she concludes, 'was easy to follow'.

Yasser returns to the three transitions and adds a further one that is particularly significant for international students: 'culture'. The format of the sessions, he notes, brought home for him that mathematics education draws on a diverse set of disciplines (he lists several including history, philosophy and psychology) and with a multiplicity of perspectives. With regard to the latter point he mentions how the use of the Activities 1-5 format in the 5 weeks on fundamental theoretical perspectives (developmental/cognitive, sociocultural/discursive, anthropological and neuroscientific/embodied) gave him a 'key' that he can now use to unlock many of the issues that concern the teaching and learning of mathematics. Mahmoud agrees and stresses that he experienced Activities 1-5 very much as an induction for an international student coming from a different setting, and in this sense this experience is 'important'. 
I now present an account of four parts of the discussion that concern the following: On learning how to identify appropriate mathematics education literature; On reading increasingly more complex writings in mathematics education; On coping with the complexity of literate mathematics education discourse; Towards a contextualised understanding of literate mathematics education discourse.

\section{On Learning How To Identify Appropriate Mathematics Education Literature}

Victoria, drawing on her own prior experiences of course design, turns to the 'transparent design' of Activities 1-5 and 'the holistic design of the course whilst working on the details in each session'. Following her cue regarding this transparency, the group elaborate their experiences of specific parts of this design. Sophia acknowledges that Activities 1-5 allow a gradual increase in degrees of freedom (e.g., to explore and choose readings from an increasing number of journals) as well as in degrees of 'difficulty': 'it wasn't like a big gap, it was something we could handle because we had done the previous.... little bit hard but it was fine'. She qualifies 'hard' as noticeable in the way the choices that the students made (resulting in their contributions to Activities $2 \mathrm{~b}, \mathrm{c}, \mathrm{d}$ ) became gradually more 'precise', as she put it gently. In fact, the group are reminded, they were rather firmly pushed towards critiquing themselves and others about these (initially weak) choices. As the instructor, I felt compelled to introduce a very simplistic thumbs up / thumbs down tactic to elicit form the initially reluctant group members a modicum of willingness to critique the choices (of papers, of examples etc.) by themselves and the other members of the group. A discourse of (initially understandable) group solidarity against instructor authority shifted very gradually towards ease with critique and an almost playfully suspenseful engagement with it in the final sessions of the module.

But then, Sophia says, this 'push' as 'helpful, because you could choose the next [paper] more precisely, and you found out how to search, to really search... because we are going to use this skill, this ability now and we will use it later, so it's going to be there'. Maalik stresses the difficulty of searching for an appropriate paper in one journal, let alone the many in mathematics education, and how the leap from one to the many is a 'different challenge'. In this sense, he concludes, the preparations for the first sessions are easier: identifying a paper aligned to the theme of the session is a well-defined and very specific task. When the choice of journals shifted to about a dozen, the challenge became formidable. But then again, Sophia observes, the requests stayed within very specific boundaries ('top journals') and kept us away from 'random' searches. Every other group member contributes comments of the same ilk on the stepwise format of the Activities.

Discussing whether engaging with searches for appropriate mathematics education literature in this manner resulted in them feeling comfortable and skilful with this type of task, the group conclude a resounding 'yes'. Discussed then whether the stepwise format of the tasks was patronising or underestimating their intelligence and capacity to operate at the standards expected of postgraduate students in mathematics education, the group also conclude with a resounding 'no'. Victoria puts it as follows: 'All you [as the instructor] were doing was assuming we were peripheral to a way of thinking and a way of doing things, and it's a way of introducing us to that', alluding to the 
Communities of Practice (Wenger 1998) perspective that was the focus of 1 week sessions. With jovial comments and laughter, the group recognise Victoria's turn of phrase as a playful way to show that the perspectives focussed on in the sessions are becoming instrumental in the ways that the students are now conceptualising their own learning.

\section{On Reading Increasingly More Complex Writings in Mathematics Education}

Sophia observes that the prescribed reading shifted from chapters in accessible texts (such as Davis and Hersh's (1980) The Mathematical Experience) to academically complex, fully-fledged journal papers (for example from Educational Studies in Mathematics). Throughout, reading a new genre (mathematics education) implied substantial complexity, and, for most of the cohort, doing so in a language (English) other than their own compounded this complexity. Further compounding of this complexity comes from the expectation (Activities 3, 4, 5) to write about, present and discuss readings. 'You have to understand it in order to present it', Sophia notes. Starting slowly from more accessible readings relieved some of the pressures and by the time the students were required to partake in reading and presenting about the (aforementioned) theoretical perspectives, the students, Sophia notes, were feeling more 'equipped' to do so. Also, Maalik notes, coming from a culture in which one is accustomed to unequivocal reliance on the teacher into a culture of learner autonomy and expectations of initiative taking (such as the tasks within Activities 1-5) is another great challenge of the transition. Even realising that understanding a text may take multiple readings can be a serious challenge in the circumstances of living multiple transitions simultaneously. I return to the multi-tier and simultaneous character of the transition lived by the students in the concluding section of the paper. But before doing so I present the final two themes that emerged from the students' written evaluation and interview data that encapsulate what to me are the more pertinent aspects of the epistemological aspects of said transition. Without wanting to underemphasise the overall success of Activities 1-5, I focus a little more on the more challenging - and initially less successful - parts of the activity set, aspects of Activities $2 b$ and $d$.

\section{On Coping With the Complexity of Literate Mathematics Education Discourse}

Taking cue from Maalik's reference to a tactic of multiple readings, the group recall other tactics they deploy towards coping with the complexity of reading in the new to them genre of mathematics education:

- First cursory reading 'to get the whole idea' and then engaging with the points made 'step by step' (Maalik, Mahmoud);

- Reading a paper once, then, especially in the cases where complex theory is being discussed, find a more practical paper that uses this theory in a more accessible way and read it, then return to a further reading of the initial paper;

- 'Writing the summary was really what made me really understand the paper' (Sophia);

- Start building a 'glossary of terms' to improve understanding of papers as the use of new terms piles up and as the presence of these terms becomes recurring (Victoria). 
I note that the non-native English speakers in the group all mention that in the initial weeks of their studies they used (rough to start with) dictionaries or internet-based translations of the texts into their native languages. Soon the roughness - or on many occasions the sheer non-sense - of the translation (or the dictionary definition in the case of native speakers) led the students to the more effortful and systematic aforementioned tactics. Yasser offers a detailed account of his trials and tribulations on this matter. The discussion of this concludes with the group also offering various instances of realizing that an English to English interpretation of a text is a much more efficient way to engage with and comprehend a text. The capacity for such interpretation is a complex one to achieve, almost regardless of whether one is doing so as a native or not speaker. As Victoria notes - who agrees fervently that most of what her non-native speaker peers describe applies in analogous terms to her - 'familiarity can be deceptive'.

\section{Towards a Contextualised Understanding of Literate Mathematics Education}

\section{Discourse}

At this juncture of the discussion, a part of Activities 1-5 receives special attention: in Activities $2 \mathrm{~b}$ and $\mathrm{d}$, the students are asked to complement their account of the readings, particularly of theoretical papers, with accounts of instances in their personal and professional experiences that can be narrated in the language of the theoretical perspective that is the focus of a particular session (Data Samples). These, the group say, were a valuable anchor to their understanding the complex theories in some of the readings. Sophia specifically talks about her attempt to construct those in terms of 'trying to write about a theory, trying it myself before I find someone else's work'.

The discussion then turns to a delicate matter: throughout the sessions, the construction and presentation of said Data Samples had been by far the less successful part of Activities 1-5. The group acknowledge this and Sophia pinpoints particularly their limited success with meeting the requirement that the Data Samples are 'written in the language' of certain theoretical perspectives. But the group are also forthcoming with ideas on how to improve this aspect of Activities 1-5. These include the following tactics:

1. Allowing more time for reflection on the discussed theories before being asked to deploy the terms of these theories in a piece of own writing. The group propose producing and discussing the Data Samples that deploy the language of the theory in Session $n$ in a practicum Session $n$ ' as opposed to moving swiftly to the theories and Data Samples of Session $n+1$.

2. Following from (1), in Session $n$ a Data Sample can be collectively prepared and presented by the group, with support from the instructor. Then students can work on Data Samples produced by small groups, independently of the instructor. Then they can do so in pairs; and then, finally, individually.

3. Following from (1) and (2), the 'ultimate, next level', Data Samples would be ones constructed and presented after visits to local schools and participating in tightly focussed small-scale field trips.

The group stress that (1) - (3) would strengthen a more stepwise approach towards fulfilling the expectation that the students produce and present their own 
Data Samples. This welcome 'turning the tables' part of the discussion ends with the group reminding me that their proposition resonates well with the overall smooth, stepwise format of Activities 1-5.

The group's propositions on how to improve the activity set are simply invaluable and several of these have been / are being incorporated in subsequent academic years. There are however at least two matters that the group's account does not elaborate much: (a) what were the reasons behind the initially limited success of this part of the activity set? (b) and, would strengthening the stepwise character of the activity alone address those reasons?

While the student written evaluation and interview data collected so far does not provide the necessary evidence for investigating these two questions further - this is certainly a worthy pursuit in subsequent phases of this work - I attempt brief responses to these in what follows, a little speculatively and drawing largely on my supervisory and post-graduate teaching experience. I deploy Sophia's comment that the most challenging aspect of the activity set was that the Data Samples are 'written in the language' of certain theoretical perspectives, as an (example) basis of these preliminary responses to (a) and (b).

With regard to (b) I expect the answer to be a reserved no. However, the application of proposed tactics (1) and (2) already for the two cohorts that followed this one has yielded some significant positive results. Analysis of these results is currently ongoing. With regard to (a) one of the difficulties that the students have been experiencing which, again, I am currently investigating further with cohorts that followed this one involves overcoming the perception of the task within Activity $2 \mathrm{~b}$ as a translation task (that is, merely re-writing a story about the learning or teaching of mathematics using the terms of the particular theory that is the focus of the module session in a particular week). This surely leaves out appreciating that the endorsement of a particular theoretical perspective implies not just deploying the language of said theoretical perspective to tell a story, but also what the story is actually about (what the narrative, written indeed in the language of said theoretical perspective drives our attention to). As I mentioned earlier the focus of this paper is on one of the three activity sets listed in the Aims and methods section (with the other two being Forming the Conceptuall Theoretical Framework of a Mathematics Education Research Project; Choosing and Applying Data Analysis Methods in Mathematics Education Research). If nothing else, the student data from the implementation and evaluation of this activity set has highlighted the pertinence of a systematic investigation of the other two.

\section{Towards Robust Research in, and Development of, Post-Graduate Supervision and Teaching Practice}

The work presented in this paper is only a modest start in what I see as a relatively novel and exciting area of research and development in post-graduate supervision and teaching practice. The present work is embedded into the growing area of support for newcomers to mathematics education research (e.g., Lester and Lambdin 2003; Thanheiser et al. 2012). A defining characteristic of this work is its focus on what was described in the preceding students' account as "living multiple transitions simultaneously". This is a characteristic that was initially dictated by the demographic make- 
up of the student cohorts participating in this study (with some mathematical qualifications in common but largely non-native speakers of English and coming from a range of cultural and educational backgrounds). However, as the study progresses, it transpires that the multi-tier and simultaneous character of the transition lived by the students is a characteristic that transcends this cohort specificity and is germane to the experiences of post-graduate students in mathematics education in a much broader sense. It is in this sense that the work presented here can be embedded into what has been highlighted (Boaler et al., ibid; Gione, ibid; Pole 1997) as the need to search for an appropriate 'research curriculum' (p.518) for post-graduate mathematics education studies . This

'could be centred more directly on the critical activities of the work [postgraduate students are expected to do] and include opportunities to develop the practices central to that work, including the knowledge and dispositions that undergird skilled design, analysis, interpretation, and communication in disciplined inquiry. Learning any complex practice requires opportunities to unpack its components in order to see what underlies competent performance' (p.518).

A particular focus in this paper has been on at least one aspect of the aforementioned multi-tier transition into post-graduate studies in mathematics education: the shifts in paradigm that students with a mathematical background experience as they enter the field of mathematics education. Activities 1-5, the Engagement With Mathematics Education Research Literature activity set that is at the heart of the discussion here alongside the other two activity sets not directly discussed - can be seen as a contribution to the growing explorations regarding said 'research curriculum'.

As the bulk of my supervisory and teaching experience is in the discipline of mathematics education, the intervention I describe and discuss in this paper is inevitably underwritten by the epistemological and pedagogical concerns that are specific to this discipline. I note however that there are analogies to be drawn in the experiences and needs of students in mathematics transitioning into mathematics education with those students in other areas, particularly those in transition from a science to a social sciences paradigm. I therefore see the potential of this research and development work as transcending the disciplinary boundaries of mathematics education - and I am not the first to see potential benefits in scope broadening on this kind (e.g., Skovsmose, Valero, and Christensen 2009). Further investigations may also address analogies between other types of transition - such as the ones discussed in (Winsløw 2009) - and explore where and how, if at all, the design principles that underpin Activities 1-5 can resonate elsewhere. University level teachers (of mathematics, but not only mathematics) now work in institutions that have an increasingly intensified focus on - as well as scholarly approach to, and accountability for - their teaching and learning practices. The search for the aforementioned 'research curriculum' (ibid.) within mathematics education has the potential to have repercussions beyond mathematics education.

Prior to such broadening of scope, however, analyses within the disciplinary boundaries of mathematics education must progress further. The work presented in this paper is currently entering its next phase in which more fine-grained analyses of the student data are in progress - their focus is on elaborating the paradigm shifts that mark the transitions experienced by the students through a focus on these as shifts in the meta- 
discursive rules and in the forms of communication (Sfard 2008; Nardi et al. 2014) enacted by the newcomers into the discourses of mathematics education research.

These further analyses will flesh out nuances, currently minimally addressed in the data accounts presented in this paper. For example, the ways in which supervisors work with individual students, how they deal with those students' specific needs and tailor their approach to these needs are profoundly personal and work such as the one sampled in this paper needs to evolve beyond its single-instructor character. Also, as the data accounts in this paper hint at, there are clear differences between different groups of students - native speakers of English or not, graduates with a purely mathematical background or not, students with variable prior teaching experience etc.. Furthermore the work presented in this paper focuses on the experiences of post-graduate students at Masters level and there are surely different elements in the experiences - and our expectations from - students at this level and at doctoral level.

As I noted earlier, the work presented in this paper is underlain by the assumption that mathematics and mathematics education are epistemologically - and in many places, institutionally - distinct disciplines. This assumption may be contestable in different parts of the academic community around the world. However, working with students, particularly those who enter mathematics education from a purely mathematical background and with minimal, if any, teaching experience, has left me with little doubt that they experience their arrival often feeling like 'all lost in a wonderland, a stranger in paradise' (Wright and Forrest 1953). I see this work, and its future incarnations, as a first step in deploying our increasing awareness of, and sensitivity to, the 'danger in [this] paradise' (ibid.), towards making possible that the students are, finally, 'strangers no more' (ibid.).

Acknowledgments I extend my sincere thanks to Sarah Dufour (University of Montreal, Canada) for her assistance during her apprenticeship visit to the Research in Mathematics Education (RME) Group in 2011-12, particularly with identifying relevant literature. I thank the postgraduate students of the RME Group, particularly the MA Mathematics Education cohorts who, since 2007, have provided the experiential basis for the work presented in this paper. Special thanks must go to the cohort who also kindly agreed to be interviewed and quoted in the paper. A preliminary report of the intervention discussed in this paper was published in the proceedings of CERME8, the $8^{\text {th }}$ Congress of European Research in Mathematics Education (Nardi 2013). The paper's reviews before - and its discussion at - the conference strongly influenced the direction that the writing has taken in this text: I am grateful to the participants of Working Group 14 (University Mathematics Education) at CERME8 for this thoughtful influence.

\section{References}

Adamson, B. Nixon, J. \& Su, F. (Eds.) (2012). The reorientation of higher education: Challenging the east-west dichotomy (CERC Studies in Comparative Education). Springer and Hong Kong University Press.

Adler, P., \& Adler, P. (2005). The identity career of the graduate student: professional socialization to academic sociology. American Sociologist, 36(2), 11-27.

Baker, V., \& Pifer, M. (2011). The role of relationships in the transition from doctoral student to independent scholar. Studies in Continuing Education, 33(1), 5-17.

Batanero, C., Godino, J. D., Steiner, H. G., \& Wenzelburger, E. (1994). The training of researchers in mathematics education. Results from an international study. Educational Studies in Mathematics, 26, 95-102.

Boaler, J., Ball, D., \& Even, R. (2003). Preparing mathematics education researchers for disciplined inquiry: Learning from, in, and for practice. In A. J. Bishop, M. A. Clements, C. Keitel, J. Kilpatrick, \& F. K. S. 
Leung (Eds.), Second international handbook of mathematics education (pp. 491-521). Dordrecht: Kluwer.

Caruana, V. \& Spurling, N. (2007). The Internationalisation of UK Higher Education: a review of selected material. Report commissioned by the HEA.

Chiappetta-Swanson, C., \& Watt, S. (2011). Good practice in the supervision \& mentoring of postgraduate students: It takes an academy to raise a scholar. USA: McMaster University.

Davis, P., \& Hersh, R. (1980). The mathematical experience. London: Penguin.

De Vita, G., \& Case, P. (2003). Rethinking the internationalisation agenda in UK higher education. Journal of Further and Higher Education, 27(4), 383-398.

Egan, R., Stockley, D., Brouwer, B., Tripp, D., \& Stechyson, N. (2009). Relationships between area of academic concentration, supervisory style, student needs and best practices. Studies in Higher Education, 34(3), 337-345.

Gunzenhauser, M. G., \& Gerstl-Pepin, C. I. (2006). Engaging graduate education: a pedagogy for epistemological and theoretical diversity. Review of Higher Education, 29(3), 319-346.

HEFCE. http://www.hefce.ac.uk/whatwedo/wp/.

Lester, F. K., \& Lambdin, D. V. (2003). From amateur to professional: The emergence and maturation of the U.S. mathematics education research community. In G. M. A. Stanic \& J. Kilpatrick (Eds.), A history of school mathematics (pp. 1629-1700). Reston: National Council of Teachers of Mathematics.

Liljedahl, P., Williams, G., Borba, M., Krzywacki, H., \& Gebremichael, A. T. (2013). Education of young mathematics education researchers. In A. M. Lindmeier \& A. Heinze (Eds.), Proceedings of the 37th conference of the international group for the psychology of mathematics education (Vol. 3, pp. 71-92). Kiel: PME.

Lovitts, Barbara, E. (2007). Making the implicit explicit - creating performance expectations for the dissertation. Virginia: Stylus Publishing.

Magyar, A., \& Robinson-Pant, A. (2011). Internationalising doctoral research: developing theoretical perspectives on practice. Teachers and Teaching: Theory and Practice, 17, 663-677.

Moschkovich, J. (2004). Appropriating mathematical practices: a case study of learning to use and explore functions through interaction with a tutor. Educational Studies in Mathematics, 55, 49-80.

Nardi, E. (2008). Amongst mathematicians: Teaching and learning mathematics at university level. New York: Springer.

Nardi, E. (2013). Shifts in language, culture and paradigm: the supervision and teaching of graduate students in mathematics education. In B. Ubuz, C. Haser, M.A. Mariotti (Eds.), Proceedings of the 8th Conference of European Researchers in Mathematics Education (pp. 2396-2405). METU: Turkey.

Nardi, E., Ryve, A., Stadler, E., \& Viirman, O. (2014). Commognitive analyses of the learning and teaching of mathematics at university level: the case of discursive shifts in the study of calculus. Research in Mathematics Education, 16(2), 182-198.

Oost, H., \& Sonneveld, H. (2007). Selected readings on Ph.D. supervision. The Netherlands: Centre for Research Schools and Graduate Schools.

Pole, C. (1997). Supervision of doctoral students in the natural sciences: expectations and experiences. Assessment \& Evaluation in Higher Education, 22(1), 49-63.

Pyhalto, K., Stubb, J., \& Lonka, K. (2009). Developing scholarly communities as learning environments for doctoral students. International Journal for Academic Development, 14(3), 221-232.

Reys, R. R. \& Kilpatrick, J. (2001). (Eds.), One Field, Many Paths: U.S. Doctoral Programs in Mathematics Education. Washington, DC: Conference Board for the Mathematical Sciences.

Sajka, M. (2003). A secondary school student's understanding of the concept of function. Educational Studies in Mathematics, 53, 229-254.

Sfard, A. (2008). Thinking as communicating. Human development, the growth of discourse, and mathematizing. New York: Cambridge University Press.

Shacham, M., \& Od-Cohen, Y. (2009). Rethinking PhD learning incorporating communities of practice. Innovations in Education and Teaching International, 46(3), 279-292.

Sharpham, J. (1993). Managing the transition to mass higher education in Australia. Long Range Planning, 26(2), $51-58$.

Sierpinska, A., \& Kilpatrick, J. (Eds.). (1998). Mathematics education as a research domain: A search for identity. Dordrecht: Kluwer.

Skovsmose, O., Valero, P., \& Christensen, O. R. (Eds.). (2009). University science and mathematics education in transition. USA: Springer.

$\mathrm{Su}, \mathrm{F}$. (2011). Chinese learning journeys: Chasing the dream. Trentham: Books.

Su, F. (2012). The international student experience in a UK university. In B. Adamson, J. Nixon, \& F. Su, (Eds.) The reorientation of higher education: Challenging the east-west dichotomy (pp. 227-245). Springer and Hong Kong University Press. 
Thanheiser, E., Ellis, A., \& Herbel-Eisenmann, B. (2012). From dissertation to publication in JRME. Journal for Research in Mathematics Education, 43(2), 144-158.

Turner, Y., \& Robson, S. (2008). Internationalizing the university. London: Continuum.

Varghese, N.V. (2012). Drivers of Reforms in Higher Education. In B. Adamson, J. Nixon, \& F. Su, (Eds.) The reorientation of higher education: Challenging the east-west dichotomy (pp. 36-49). Springer and Hong Kong University Press.

Wenger, E. (1998). Communities of practice: Learning, meaning and identity. Cambridge: Cambridge University Press.

Winsløw, C. (2009). First years of teaching. In R. Evens \& D. Ball (Eds.), The professional education and development of teachers of mathematics (pp. 93-101). New York: Springer.

Wright, R. \& Forrest, G. (1953). Stranger in Paradise (lyrics). In R. Wright \& Forrest, G. Kismet [Destiny], Broadway musical and Metro Goldwyn Mayer film (1955). Accessed at http://www.lyrics.net/lyric/ 24487476 on 22 January 2015. 